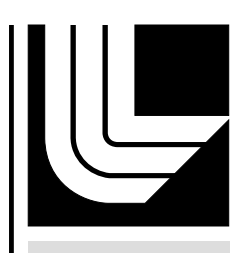

LAWRENCE LIVERM ORE N A TIO NAL LABORATORY

Purple L1 Milestone Review Panel: GPFS Functionality and Performance

W. E. Loewe

December 4, 2006 
This document was prepared as an account of work sponsored by an agency of the United States Government. Neither the United States Government nor the University of California nor any of their employees, makes any warranty, express or implied, or assumes any legal liability or responsibility for the accuracy, completeness, or usefulness of any information, apparatus, product, or process disclosed, or represents that its use would not infringe privately owned rights. Reference herein to any specific commercial product, process, or service by trade name, trademark, manufacturer, or otherwise, does not necessarily constitute or imply its endorsement, recommendation, or favoring by the United States Government or the University of California. The views and opinions of authors expressed herein do not necessarily state or reflect those of the United States Government or the University of California, and shall not be used for advertising or product endorsement purposes.

This work was performed under the auspices of the U.S. Department of Energy by University of California, Lawrence Livermore National Laboratory under Contract W-7405-Eng-48. 


\section{Purple L1 Milestone Review Panel GPFS Functionality and Performance Bill Loewe, 12/1/2006}

\section{Deliverable}

The GPFS deliverable for the Purple system requires the functionality and performance necessary for ASC I/O needs. The functionality includes POSIX and MPIIO compatibility, and multi-TB file capability across the entire machine. The bandwidth performance required is $122.15 \mathrm{~GB} / \mathrm{s}$, as necessary for productive and defensive $\mathrm{I} / \mathrm{O}$ requirements, and the metadata performance requirement is 5,000 file stats per second.

\section{Criteria}

To determine success for this deliverable, several tools are employed. For functionality testing of POSIX, 10TB-files, and high-node-count capability, the parallel file system bandwidth performance test IOR is used. IOR is an MPI-coordinated application that can write and then read to a single shared file or to an individual file per process and check the data integrity of the file(s). The MPIIO functionality is tested with the MPIIO test suite from the MPICH library.

Bandwidth performance is tested using IOR for the required $122.15 \mathrm{~GB} / \mathrm{s}$ sustained write. All IOR tests are performanced with data checking enabled. Metadata performance is tested after "aging" the file system with $80 \%$ data block usage and $20 \%$ inode usage. The fdtree metadata test is expected to create/remove a large directory/file structure in under 20 minutes time, akin to interactive metadata usage. Multiple (10) instances of "ls -lR", each performing over $100 \mathrm{~K}$ stats, are run concurrently in different large directories to demonstrate 5,000 stats/sec.

\section{$\underline{\text { Results }}$}

In November, 2005, the Purple acceptance test was performed on a 1024-node system with 3 metadata servers and $101 \mathrm{I} / \mathrm{O}$ servers. The functionality testing was completed successfully.

In April, 2006, on the full 2.0 PB Purple file system with 3 metadata servers and $125 \mathrm{I} / \mathrm{O}$ servers, IOR showed file-per-process performance rates of $73 \mathrm{~GB} / \mathrm{s}$ for write and 115 $\mathrm{GB} / \mathrm{s}$ for read on 512 nodes to $16 \mathrm{~GB}$-files. The single-shared-file performance was 129 $\mathrm{GB} / \mathrm{s}(\mathrm{W})$ and $153 \mathrm{~GB} / \mathrm{s}(\mathrm{R})$ for 1024 nodes to an 8TB-file.

In September, 2006, a single 1.4 PB GPFS file system (/p/gscratch3) using the upgraded I/O subsystem with 3 metadata servers and half the available I/O servers was tested. For the metadata performance, the "ls $-1 \mathrm{R}$ " performance was $10,000 \mathrm{stats} / \mathrm{sec}$ in aggregate on 10 nodes. The fdtree test completed in 16 minutes as well. This satisfied the metadata performance requirements. 
In addition, application testing was performed under load using UMT2K on 1024 nodes (4096 processors) writing $1.4 \mathrm{~TB}$ of file data per timestep while IOR was repeatedly writing shared 40TB-files from 300 nodes (300 processors). While running simultaneously, the lowest reported UMT2K performance was $\sim 59 \mathrm{~GB} / \mathrm{s}$, while the lowest IOR reported was $\sim 19 \mathrm{~GB} / \mathrm{s}$ to the same file system.

Further, on this file system using half of the total I/O servers, IOR showed file-perprocess performance rates of $71 \mathrm{~GB} / \mathrm{s}$ for write on 1024 nodes to $40 \mathrm{~GB}$-files. The singleshared-file performance was $71 \mathrm{~GB} / \mathrm{s}$ for writing from 512 nodes to a shared 20TB-file.

In November, 2006 the second 1.4 PB GPFS file system (/p/gscratch4) using the other half of the I/O servers was complete. Running across both of these file systems (/p/gscratch3 and /p/gscratch4) in a file-per-process pattern (even tasks writing their files to one file system, odd to the other) achieved $131 \mathrm{~GB} / \mathrm{s}$ write performance on 500 nodes writing $10 \mathrm{~GB}$ files. 800 nodes reading $10 \mathrm{~GB}$ files achieved $139 \mathrm{~GB} / \mathrm{s}$. This satisfied the $122 \mathrm{~GB} / \mathrm{s}$ requirement.

\section{Conclusion}

The functionality and performance requirements were met for Purple's GPFS. The file system passed the POSIX and MPIIO functionality requirements. As well, the metadata performance results satisfied the requirement of 5,000 stats per second and fdtree completion in under 20 minutes. For the bandwidth performance, no data integrity issues were encountered during the testsing, and the $122.15 \mathrm{~GB} / \mathrm{s}$ was satisfied with over 130 $\mathrm{GB} / \mathrm{s}$ write performance. 